3 Tsui BCH, Gupta S, Finucane B. Confirmation of epidural catheter placement using nerve stimulation in obstctric parients: the Tsui test. (Abstract) Reg Anesth 1998; 23S: 35.

\section{Transthoracic echocardiography in perioperative medicine}

To the Editor:

With the growing trend towards minimal preoperative testing, we commonly encounter ambulatory surgery patients with incomplete preoperative assessments. ${ }^{1}$ Medical consultations on the day of surgery (with or without additional testing), almost inevitably result in postponement or disruption of the planned surgical procedure.

Recent practice guidelines suggest that a transthoracic echocardiography (TTE) examination is often sufficient to exclude major cardiac pathology in patients scheduled to undergo surgical procedures with low cardiac risk. ${ }^{1}$ Echocardiography allows one

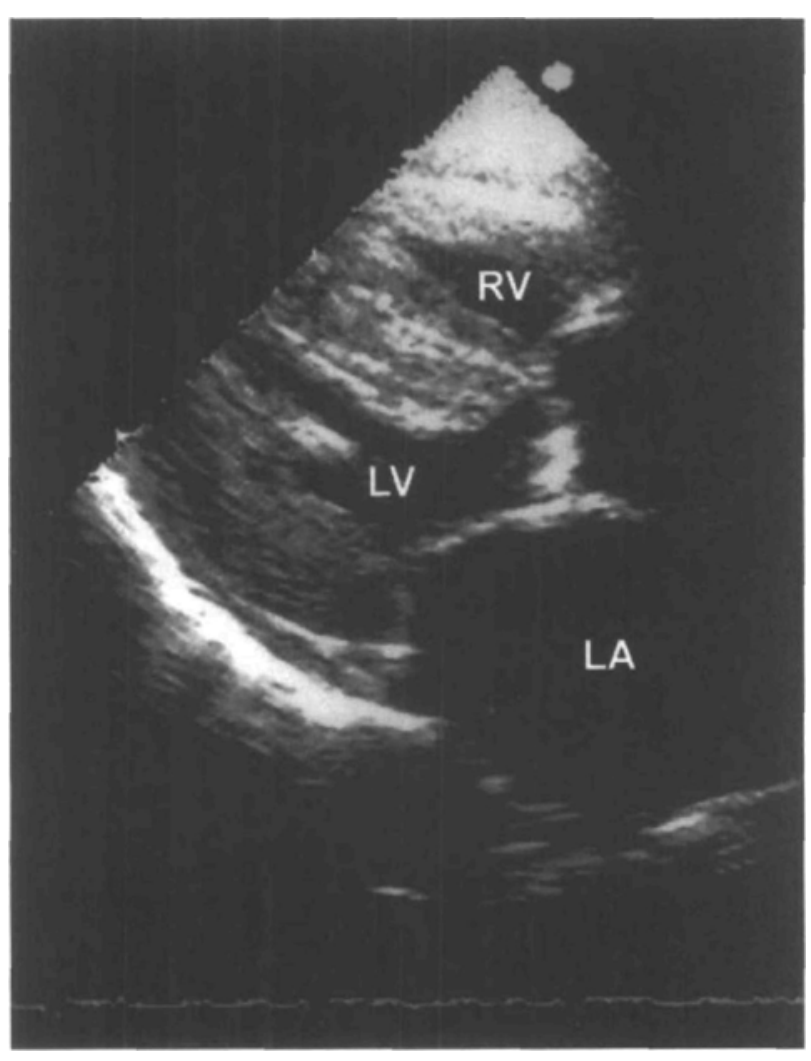

FIGURE Parasternal long axis two-dimensional echocardiogram demonstrates marked hypertrophy of the left ventricle with small left ventricular cavity.

Legend: LA- Left atrium, L V- Left ventricle, R V-Right ventricle to confirm or rule out common cardiac causes of dyspnea, such as left ventricular hypertrophy, valvular disease, diastolic dysfunction, cardiomyopathy, all of which represent major clinical predictors of cardiac risk. ${ }^{1,2}$

After formal training in the echocardiography laboratory, ${ }^{3}$ several anesthesiologists in this department have become adept in the performance of a basic TTE examination. They recently used echocardiographic equipment from the operating room to exclude severe aortic stenosis in one patient, left ventricular dysfunction in another, and to diagnose hypovolemia in a third (Figure). ${ }^{4}$ The information obtained by TTE greatly facilitated patient care. It prevented unnecessary delays of surgery and additional testing in the first two patients. Hospitalization, invasive monitoring and an extensive cardiac work-up were avoided in the third patient.

While, traditionally, anesthesiologists have not considered TTE within the scope of their practice or knowledge, new economic realities and the wish to be perceived as perioperative physicians, may force a reassessment. ${ }^{5}$ For anesthesiologists to become effective as perioperative physicians, anesthesia training may need to be adjusted to also include formal instruction in TTE.

\section{Admir Hadi MD PhD \\ Jerry D. Vloka MD PhD \\ Robert Koorn MD \\ Daniel M. Thys MD \\ New York, NY, USA}

\section{References}

1 Guidelines for perioperative cardiovascular evaluation for noncardiac surgery. Report of the American College of Cardiology/American Heart Association Task Force on Practice Guidclines. (Committee on Perioperative Cardiovascular Evaluation for Noncardiac Surgery) J Am Coll Cardiol 1996; 27: 910-48.

2 ACC/AHA Guidelines for the clinical application of echocardiography. A Report of the American College of Cardiology/American Heart Task Force on Practice Guidelines. Circulation 1997; 95: 1686-744.

3 Guidelines for optimal physician training in echocardiography. Recommendations of the American Society of Echocardiography Committee for Physician Training in Echocardiography. Am J Cardiol 1987; 60: 158-63.

4 Hadi A, Vloka ME, Vloka JD, Koorn R, Krasnow $N$, Hillel $Z$. Peri-operative echocardiography in the ambulatory anesthesia setring. Anesth Analg 1998; 86; $S 9$.

5 Longnecker DE. Navigation in uncharted waters. Is anesthesiology on course for the 21st century? Anesthesiology 1997; 86: 736-42. 